\title{
MORFOLOGI POLEN VEGETASI MANGROVE DI DESA SALO PALAI KEC. MUARA BADAK KAB. KUTAI KARTANEGARA
}

\author{
Titin Yuliana, Syafrizal, Nova Hariani* \\ Program Studi Biologi FMIPA Universitas Mulawarman \\ *E-mail: nova.ovariani@gmail.com
}

\begin{abstract}
This study aims to identified pollen morphology of Mangrove vegetation in Salo Palai Village, Muara Badak Sub District, Kutai Kartanegara District was done in May until July. This study using acetolisis method. Data obtained were analyzed with qualitative descriptive method to observed the shape, ornaments and also aperture. This method is measuring size, the length of the polar axis to the equatorial diameter. The result obtained shape and pollen unit is monad subspheroidal. There are size medium pollen and size large pollen. The ornaments including of 7 psilate, 2 reticulate and 2 ekinate. The aperture including of 4 inaperture, 2 tricolporate, 1 tricolpate, 1 triporate, 1 tetraporate, 1 monoporate and 1 stephanocolporate.

Keywords: Vegetation, Mangrove, Pollen, Association, Identification.
\end{abstract}

Desa Salo Palai yang terletak di Kecamatan Muara Badak Kabupaten Kutai Kartanegara merupakan salah satu daerah yang berada di pesisir pantai sehingga memiliki keragaman jenis tumbuhan pinggir pantai termasuk mangrove. Luas Desa Salo Palai berdasarkan data yang didapat adalah 9.976 Ha (Desa Salo Palai, 2016) dimana mangrove daerah tersebut tersebar tidak pada satu tempat saja.

Mangrove didefinisikan sebagai tumbuhan atau komunitas yang terdapat di daerah pasang surut, juga didefinisikan sebagai formasi tumbuhan daerah litoral yang khas di pantai daerah tropis dan subtropis yang terlindung (Noor et al., 1999). Jenis-jenis vegetasi di hutan mangrove terdiri dari mangrove sejati/mayor dan mangrove asosiasi. Mangrove sejati merupakan jenis tanaman yang hidup di wilayah pasang surut dan mampu menyerap zat garam sekaligus memiliki sistem adaptasi mengeluarkan kelebihan zat garam yang tidak dibutuhkan melalui batang dan daunnya. Mangrove asosiasi atau tumbuhan pesisir pantai merupakan jenis tanaman yang mampu beradaptasi dengan ekosistem pantai namun yang menjadi pembeda dari mangrove sejati adalah ketidakmampuan mengeluarkan kelebihan zat garam dari dalam tubuh (Kitamura, 2003).

Polen atau serbuk sari adalah sel gamet jantan pada bunga yang berbentuk butir-butir halus berwarna kuning yang dihasilkan oleh 
tumbuhan berbunga (Spermatophyta) yang terdapat di ujung benang sari bunga. Serbuk sari merupakan alat penyebaran dan perbanyakan generatif dari tumbuhan berbunga. Sifat dan ciri morfologi polen dapat digunakan untuk mengidentifikasi suatu takson pada tingkat famili, genus bahkan sampai tingkat spesies (Erdmant, 1972).

Bentuk butir serbuk sari dapat dicandra menggunakan kenampakan pada pandangan polar dan pandangan ekuatorial. Bentuk serbuk sari dapat pula ditentukan berdasarkan perbandingan antara panjang aksis polar (P) dan diameter ekuatorial (E), atau Indeks P/E (Moore dan Webb, 1978 dalam Susandarini, 2004).

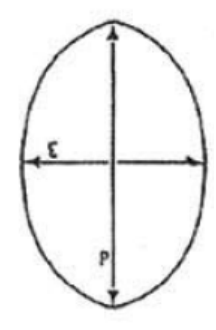

\begin{tabular}{ll} 
P/E & Shape \\
Index & Class \\
$>2.0$ & Perprolate \\
1.33 .2 .0 & Prolate \\
$0.75-1.33$ & Subspheroidal \\
$0.50-0.75$ & Oblate \\
$<0.5$ & Peroblate \\
Example : & \\
\multicolumn{2}{c}{$\mathrm{P} / \mathrm{E}=3 / 2=1.5$}
\end{tabular}

Gambar 1. Bentuk polen berdasarkan Indeks P/E (Susandarini, 2004).

Menurut Erdtman (1952), dalam Rahmayuna (2009), ukuran polen dan spora ditentukan berdasarkan pengukuran aksis yang terpanjang yang dibagi menjadi enam kelompok ukuran, yaitu :

- Sangat kecil $=<10 \mu \mathrm{m}$

- Kecil = $10-25 \mu \mathrm{m}$

- Sedang $=25-50 \mu \mathrm{m}$

- Besar $=50-100 \mu \mathrm{m}$

- Sangat besar $\quad=100-200 \mu \mathrm{m}$

- Raksasa $\quad=>200 \mu \mathrm{m}$.

Unit serbuk sari dibedakan atas : monad, diad, tetrad dan polyad. Selain itu ada pula serbuk sari yang dilepaskan dari tumbuhan dalam bentuk masal atau polinia. Serbuk sari tetrad dibedakan ke dalam lima tipe, yaitu: tetrahedral, tetragonal, rhomboid, decussata dan tetrad silang. Aperture merupakan suatu area tipis pada eksin, yang berlangsung atau tidak langsung berhubungan dengan pertunasan. Aperture polen dibedakan menjadi dua tipe, yaitu yang celah memanjang (kolpus) dan yang merupakan celah pendek, atau berbentuk bulat (porus), sedangkan polen yang tidak mempunyai aperture disebut non aperture (Syafrizal, 2001).

Ornamentasi merupakan

bentuk eksternal eksin tanpa menunjukkan susunan eksin bagian dalam. Menurut Fagri dan Iversen (1975), ornamentasi termasuk dalam skluptur eksin yang timbul karena adanya keanekaragaman bentuk morfologi dari rektum. Pencandraan tipe ornamentasi eksin dibuat berdasarkan ukuran, bentuk dan unsur ornamentasinya. Berdasarkan uraian diatas peneliti tertarik untuk melakukan penelitian terhadap morfologi polen vegetasi mangrove yang berada di Desa Salo Palai Kecamatan Muara Badak. Penelitian diharapkan dapat memberi informasi tentang morfologi polen dan keanekaragaman jenis mangrove yang berada di wilayah tersebut.

\section{METODE}

1. Waktu dan Tempat

Penelitian dilakukan pada bulan Mei-Juli 2016 di hutan mangrove Desa Salo Palai, Kecamatan Muara Badak, Kabupaten Kutai Kartanegara, Kalimantan 
Timur serta pengamatan di Laboratorium Anatomi dan Sistematika Tumbuhan, Fakultas Matematika dan Ilmu Pengetahuan Alam Universitas Mulawarman, Samarinda.

2. Alat dan Bahan

Alat yang digunakan dalam penelitian ini yaitu : kantong plastik, plastik klip, plastik herbarium, botol sampel, cawan petri, object glass, cover glass, pipet tetes, pipet volume, buku identifikasi, mikroskop Zeizz 2012, komputer, oven, botol spray, jarum, alat tulis dan kamera.

Bahan yang digunakan dalam penelitian ini yaitu : serbuk sari (polen), Asam Asetat Glasial (AAG), alkohol 70\%, kertas label, kuteks, tali rafia, benang wol, kertas koran dan kertas herbarium.

3. Prosedur Kerja

a. Pengambilan sampel di lapangan

Tumbuhan mangrove yang didapat dibuat herbariumnya, bunga dikoleksi selain dibuat herbarium juga disimpan dalam plastik klip dan diberi kertas label, kemudian dibawa ke laboratorium untuk diamati polennya.

b. Preparasi serbuk sari atau polen (metode asetolisis)

Bunga yang diperoleh dari lapangan, masing-masing diambil polen dari anther dan dikumpulkan dalam cawan petri. Polen dimasukkan ke dalam botol sampel kemudian diberi label, ditambahkan ke dalamnya Asam Asetat Glasial sebanyak $5 \mathrm{ml}$. Lalu sampel divibrasi menggunakan alat vibrator \pm 3 jam. Pengambilan sampel dilakukan ditiga bagian botol sampel dengan masing-masing bagian diambil 1 tetes pada bagian atas, pada bagian tengah, pada bagian bawah, lalu diteteskan di atas object glass yang telah dibersihkan dan ditutup dengan cover glass. Kemudian diamati menggunakan mikroskop binokuler phototube ZEISS 2012.

c. Pengamatan

Pengamatan preparat tersebut diamati menggunakan mikroskop binokuler phototube ZEISS dengan perbesaran 40x10. Bulir polen yang diamati lalu difoto menggunakan kamera mikroskop dan diukur panjang aksis polar serta ekuator polen menggunakan program ZEN lite 2012 yang berada di dalam komputer dengan satuan $\mu \mathrm{m}$. Data yang diperoleh dianalisis dengan metode deskriptif kualitatif yaitu dengan melihat bentuk, ornamen serta apertur dan metode deksriptif kuantitatif yaitu dengan ukuran, mengukur panjang aksis polar dan diameter bidang equatorial polen.

\section{HASIL DAN PEMBAHASAN}

Berdasarkan hasil penelitian yang telah dilakukan, diperoleh tumbuhan mangrove yang terdapat di Desa Salo Palai Kecamatan Muara Badak yaitu 11 spesies. Data pengoleksian dapat dilihat pada Tabel 1 dan morfologi polen dapat dilihat pada Tabel 1.Pada penelitian ini didaapatkan tumbuhan mangrove dan tumbuhan asosiasi. Namun yang mendominasi adalah tumbuhan mangrove, dilihat dari susunan vegetasi yang ditemukan seperti Avicennia officinalis L., Avicennia alba Blume., Bruguiera gymnorhiza Lamk., Rhizophora mucronata Lamk., Lumnitzera littorea (Jack) Voight, Sonneratia alba Smith., 
Schyphiphora hydrophyllacea Gaertn.f.. Hal tersebut diperkuat oleh pernyataan Nobbs dan McGuinness (1999) yang menyebutkan bahwa ciri utama dari hutan mangrove adalah adanya genus Avicennia, Bruguiera dan beberapa spesies dari genus Rhizophora.

Tumbuhan asosiasi disusun oleh vegetasi Acacia auricoliformis A. Cunn., Chromolaena odorata L., Melastoma malabatrichum L., Hibiscus tiliacius L.. Hal ini disebabkan bahwa pada lokasi penelitian terdapat daerah transisi antara hutan mangrove dan daratan. Dan diperkuat oleh pernyataan Tomlinson (1986) yang menyebutkan bahwa vegetasi asosiasi adalah jenis-jenis yang dapat terpancarkan oleh arus air laut dan biasa ditemukan di zona transisi antara hutan mangrove dan darat.

Polen diidentifikasi

berdasarkan ciri-ciri morfologi yang meliputi bentuk, ukuran, apertur dan ornamen yang merupakan ciri utama untuk membedakan antar spesies tumbuhan. Berdasarkan ratio indeks $\mathrm{P} / \mathrm{E}$ pada tumbuhan mangrove, diperoleh jenis Avicennia officinalis L. jumlah kisaran polen 1,14 $\mu \mathrm{m}$, Avicennia alba Blume. memiliki bentuk ukuran 1,01 $\mu \mathrm{m}$, Bruguiera gymnorhiza Lamk. memiliki bentuk ukuran 1,11 $\mu \mathrm{m}, \quad$ Rhizophora mucronata Lamk. memiliki ukuran 1,04 $\mu \mathrm{m}$, Lumnitzera littorea (Jack) Voight. memiliki ukuran 1,10 $\mu \mathrm{m}$, Sonneratia alba Smith. memiliki ukuran 1,30 $\mu \mathrm{m}, \quad$ Schyphiphora hydrophyllacea Gaertn.f. memiliki ukuran $1,13 \mu \mathrm{m}, \quad$ Acacia auricoliformis A. Cunn. memiliki ukuran 1,13 $\mu \mathrm{m}, \quad$ Chromolaena odorata L. memiliki ukuran $1,03 \mu \mathrm{m}$, Melastoma malabatrichum L. memiliki ukuran $1,08 \mu \mathrm{m}$ dan Hibiscus tiliacius L. memiliki ukuran $1,00 \mu \mathrm{m}$. Secara umum tumbuhan mangrove memiliki sifat unit dan bentuk yang sama pada seluruh jenis yaitu monad dan subspheroidal, dengan indeks $\mathrm{P} / \mathrm{E}$ antara 1,00-1,14 $\mu \mathrm{m}$. Menurut Kapp,1969 dalam Susandarini, 2004) , bentuk polen yang memiliki indeks P/E 0,75-1,33 $\mu \mathrm{m}$ termasuk dalam subspheroidal.

Berdasarkan ukuran pada polen, terdapat beberapa pembagian ukuran polen mulai dari ukuran yang sangat kecil sampai dengan ukuran raksasa. Pembagian ini berdasarkan pembagian ukuran menurut kelasnya yang memiliki aksis terpanjang. Dari hasil pengamatan polen yang diperoleh polen berukuran sedang dan besar. Polen berukuran sedang berkisar 25-50 $\mu \mathrm{m}$ terdapat pada Avicennia officinalis L., Avicennia alba Blume, Rhizophora mucronata Lamk., Lumnitzera littorea (Jack) Voight., Sonneratia alba Smith., Schyphiphora hydrophyllacea Gaertn.f., Acacia auriculiformis A. Cunn., Chromolaena odorata L. dan Melastoma malabathricum L.. Polen berukuran besar berkisar antara 50-100 $\mu \mathrm{m}$ terdapat pada Bruguiera gymnorhiza Lamk. dan Hibiscus tilliacius L.. Menurut Susandarini (2004), ukuran yang digolongkan dalam ukuran kecil apabila memiliki ukuran berkisar antara 10-25 $\mu \mathrm{m}$, ukuran besar berkisar 50-100 $\mu \mathrm{m}$. 
Tabel 1. Jenis dan ciri morfologi polen vegetasi manggrove di desa Salo Palai Kec. Muara Badak Kalimantan Timur

\begin{tabular}{|c|c|c|c|c|c|c|c|c|c|c|}
\hline \multirow{3}{*}{ No. } & \multirow{3}{*}{ Famili dan Spesies } & \multirow{3}{*}{ Nama Lokal } & \multirow{3}{*}{ Unit } & \multirow{3}{*}{ Bentuk } & \multirow{3}{*}{$\begin{array}{l}\text { Kategori } \\
\text { Ukuran }\end{array}$} & \multicolumn{5}{|c|}{ Ciri-ciri Morfologi } \\
\hline & & & & & & \multicolumn{2}{|c|}{ Ukuran $(\mu \mathrm{m})$} & \multirow[t]{2}{*}{$\mathbf{P} / \mathbf{E}$} & \multirow[t]{2}{*}{$\begin{array}{c}\text { Ornamentas } \\
\text { i }\end{array}$} & \multirow[t]{2}{*}{ Aperture } \\
\hline & & & & & & $\mathbf{P}$ & $\mathbf{E}$ & & & \\
\hline \multirow{3}{*}{1.} & Tumbuhan Mangrove & & & & & & & & & \\
\hline & Avicennia officinalis L. & Api-api ludat & Monad & Subspheroidal & Sedang & 40,21 & 35,22 & 1,14 & Reticulate & Tricolporate \\
\hline & $\begin{array}{l}\text { Avicennia alba Blume. } \\
\text { Rhizophoraceae }\end{array}$ & Api-api putih & Monad & Subspheroidal & Sedang & 42,06 & 41,40 & 1,01 & Psilate & Inaperture \\
\hline \multirow{2}{*}{2.} & Bruguiera gymnorhiza Lamk. & Bakau daun besar & Monad & Subspheroidal & Besar & 64,02 & 57,87 & 1,11 & Psilate & Inaperture \\
\hline & $\begin{array}{l}\text { Rhizophora mucronata Lamk. } \\
\text { Combretaceae }\end{array}$ & Bakau hitam & Monad & Subspheroidal & Sedang & 25,11 & 24,03 & 1,04 & Reticulate & Inaperture \\
\hline 3. & Lumnitzera littorea (Jack) Voight. & Api-api uding & Monad & Subspheroidal & Sedang & 36,60 & 33,23 & 1,10 & Psilate & Tricolpate \\
\hline \multirow{2}{*}{$\begin{array}{l}4 . \\
5 .\end{array}$} & Sonneratia alba Smith. & Bogem & Monad & Subspheroidal & Besar & 51,05 & 39,26 & 1,30 & Psilate & Inaperture \\
\hline & $\begin{array}{l}\text { Rubiaceae } \\
\text { Schyphiphora hydrophyllacea Gaertn.f. } \\
\text { Tumbuhan Asosiasi }\end{array}$ & Cinggam & Monad & Subspheroidal & Sedang & 32,05 & 28,12 & 1,13 & Psilate & Triporate \\
\hline 6. & $\begin{array}{l}\text { Fabaceae } \\
\text { Acacia auricoliformis } \mathrm{L} . \\
\text { Asteraceae }\end{array}$ & Akasia & Monad & Subspheroidal & Sedang & 41,87 & 36,86 & 1,13 & Psilate & Tetraporate \\
\hline \multirow{3}{*}{9.} & $\begin{array}{l}\text { Chromolaena odorata } \mathrm{L} \text {. } \\
\text { Melastomaceae }\end{array}$ & Kirinyuh & Monad & Subspheroidal & Sedang & 22,81 & 22,19 & 1,03 & Ekinate & Tricolporate \\
\hline & $\begin{array}{l}\text { Melastoma malabatrichum } \mathrm{L} . \\
\text { Malvaceae }\end{array}$ & Karamunting & Monad & Subspheroidal & Sedang & 26,63 & 24,60 & 1,08 & Psilate & Monoporate \\
\hline & Hibiscus tiliaceus $\mathrm{L}$. & Waru lengis & Monad & Subspheroidal & Besar & 96,32 & 96,05 & 1,00 & Ekinate & Stephanocolporate \\
\hline
\end{tabular}


Secara umum dari semua spesies masing-masing butiran polen yang didapat memiliki ciri morfologi dinding polen yang berbeda. Dilihat dari apertur pada spesies Avicennia alba Blume., Bruguiera gymnorhiza Lamk., Rhizophora mucronata Lamk. dan Sonneratia alba Smith. memiliki tipe apertur inaperture karena tidak memiliki apertur. Avicennia officinalis L. dan Chromolaena odorata L. memiliki tipe apertur tricolporate karena memiliki bentuk gabungan antara bentuk triporate dan tricolpate dengan memiliki ketiga sisi yang saling berhadapan dan memiliki colpus dan porus. Lumnitzera littorea (Jack) Voight. Memiliki tipe apertur tricolpate karena memiliki bentuk tiga sisi yang berhadapan dengan bentuk memanjang. Schyphiphora hydrophyllacea Gaertn.f. memiliki tipe apertur triporate karena memiliki tiga sisi yang berhadapan dengan bentuk bulat. Acacia auriculiformis A.Cunn. memiliki tipe apertur tetraporate karena memiliki empat sisi yang berhadapan dengan bentuk bulat. Melastoma malabathricum L. memiliki tipe apertur monoporate karena memiliki satu sisi dengan bentuk bulat. Hibiscus tilliacius L. memiliki tipe aperture stephanocolporate karena memiliki bentuk seperti duri.

Menurut Kapp (1969), tipe ornamen bervariasi, yaitu ornamen psilate memiliki seluruh permukaan yang halus, rata dan licin yaitu pada Avicennia alba Blume., Bruguiera gymnorhiza Lamk., Lumnitzera littorea (Jack) Voight., Sonneratia alba Smith., Schyphiphra hydrophyllacea Gaertn.f., Acacia auriculiformis A. Cunn. dan Melastoma malabathricum L.. Tipe ornamen reticulate memiliki unsur ornamentasi membentuk pola seperti jala yaitu pada Avicennia officinalis L. dan Rhizophora mucronata Lamk.. Tipe ornamen ekinate memiliki unsur ornamentasi berbentuk seperti duri yaitu pada Chromolaena odorata L. dan Hibiscus tilliacius L.

\section{SIMPULAN DAN SARAN}

Berdasarkan hasil penelitian yang telah dilakukan di Desa Salo Palai Kecamatan Muara Badak dapat disimpulkan bahwa :

1. Ditemukan 11 spesies tumbuhan yang terdiri dari tujuh spesies tumbuhan mangrove dan empat spesies tumbuhan asosiasi.

2. Bentuk unit polen yang ditemukan di vegetasi mangrove yaitu monad, subspheroidal. Ukuran polen yaitu berukuran sedang dan besar. Pada ornamen terdiri dari psilate tujuh, reticulate dua dan ekinate dua. Pada apertur terdiri dari inaperture empat, tricolporate dua, tricolpate satu, triporate satu, tetraporate satu, monoporate satu dan stephanocolporate satu.

\section{DAFTAR PUSTAKA}

Erdmant, G. (1972). Pollen Morphology and Plant Taxonomy. London: Hafiner Publishing Company.

Faegri, K. dan Johs. Iversen. (1989). Text Book of Pollen Analysis. London: Alden Press.

Gil nelson, (2011). The Trees of Florida. Sarasotam Florida: Pineapple Press..

Irma, R. C. (2006). Families of Common Flowering Plants in 
the Philippines. Quezon City: The University of Philippines Press.

Kitamura, S. (2003). Buku Panduan Mangrove di Indonesia. Denpasar: Departemen Kehutanan Indonesia International.

Moreira-Muñoz, A. \& Muñoz-Schick, M. (2007). Classification, Diversity, and Distribution of Chilean Asteraceae: Implications for Biogeography and Conservation. Blackwell Publishing Ltd, Chili.

Nobbs, M \& Mcguinness, K. (1999). Developing methods for quantifying the apparent abundance of fiddler crabs (Ocypodidae: $U c a$ ) in mangrove habitats. Journal of Austral Ecology. Vol. 24, No. 1, 43-49.

Noor, Y. R, Khazali, M., \& Suryadiputra, I. M. (1999). Panduan Pengenalan Manrove di Indonesia. Bogor: Wetlands International Indonesia Programme.
Pertiwi, R. H. (2015). Studi Palinologi Famili Asteraceae di Kebun Raya Universitas Mulawarman Samarinda (KRUS). Samarinda: Fakultas Matematika dan Ilmu Pengetahuan Alam Universitas Mulawarman.

Rusfidra, A. (2006). Tanaman Pakan Lebah Madu. Retrieved April 9, 2016, from http://www.bungahatta.ac.id.

Syafrizal, (2001). Analisis Palinologi Perlapisan Batubara Formasi Balikpapan Jalur Mernadai Teluk Dalam di Areal Yambang PT. Bukit Baiduri Enterprise Kabupaten Kutai Kalimantan Timur. Samarinda: $\quad$ Fakultas Kehutanan, Universitas Mulawarman,

Susandarini, R. (2004). Pengantar Palinologi. Retrieved Maret 19, 2016, from http://elisa.ugm.ac.id.

Tomlinson, P. B. (1986). The Botany of Mangroves. Inggris: Cambridge University Press. 